\title{
Kronik Gastrik Volvulus
}

\author{
Chronic Gastric Volvulus \\ Hasan ÇALIŞ ${ }^{1}$, Okan ERDOĞAN² ${ }^{2}$, Mehmet Kemal ÖĞÜş² \\ ${ }^{1}$ Antalya Eğitim ve Araştırma Hastanesi, Genel Cerrahi Kliniği, Antalya \\ ${ }^{2}$ Akdeniz Üniversitesi Tıp Fakültesi, Genel Cerrahi AD, Antalya
}

\section{öz}

Gastrik volvulus, midenin kendi ekseni etrafında anormal rotasyonu sonucu gelişen ve oldukça nadir görülen bir durumdur. Akut, kronik ve kronik zeminde akut volvulus şeklinde olabilir. Kronik gastrik volvulus sıklıkla geç tanı almaktadır. Karın ağrısı, distansiyon ve kilo kaybı şikayetleriyle 3 yıldır farklı kliniklere başvuran ve kronik gastrik volvulus tanısı alan olgu sunuldu.

Anahtar Kelimeler: Volvulus, mide, gastroskopi

\begin{abstract}
Gastric volvulus is a rare clinical entity defined as an abnormal rotation of the stomach around its own axis. It can be acute, chronic and acute on chronic. Chronic gastric volvulus is often diagnosed late. We present a case of gastric volvulus complaining of abdominal pain, distension and weight loss addmitted different clinics for three years.
\end{abstract}

Keywords: Volvulus, stomach, gastroscopy 


\section{Giriş}

Gastrik volvulus, midenin kendi ekseni etrafında anormal rotasyonu sonucu gelişen ve oldukça nadir görülen bir durumdur (1). Akut, kronik ve kronik zeminde akut volvulus şeklinde görülebilir (2). Akut gelişen gastrik volvulus vakalarında tanı ve tedavide gecikme olması durumunda iskemi ve nekroz gelişimiyle perforasyon oluşabilir. Böyle durumlarda yüksek mortalite oranları bildirilmiştir. Kronik gastrik volvulus vakaları ise distansiyonla birlikte olan epigastriumda ağrı, öğürme, kusma ve kilo kaybı şikayetleriyle sıklıkla geç tanı alabilmektedirler (3). Karın ağrısı, distansiyon ve kilo kaybı şikayetleriyle 3 yıldır farklı kliniklere başvuran ve kronik gastrik volvulus tanısı alan olgu sunuldu.

\section{OLGU SUNUMU}

Epigastrik bölgede karın ağrısıyla birlikte distansiyon, kusma, yaklaşık 5 kg kilo kaybı şikayetleri olan ve 3 yıldır farklı kliniklerce değerlendirilen 32 yaşındaki bayan olgu kliniğimize başvurdu. Yapılan fizik muayenesinde patolojik bulgu saptanmayan olgunun laboratuar testleri normal sınırlardaydı ve sistemik sorgulamasında peptik ülser ve diafragma hernisi yönünden aile öyküsü bulunmamaktaydı. Olgunun yapılan gastroskopisinde mide içinde belirgin sıvı olup mide korpusu posterior duvar üzerine kıvrımlıydı, yapılan manüplasyonlarda pilora ulaşılamadı. Gastrik volvulus ön tanısıyla yapılan baryumlu özofagus ve mide görüntülemesinde midede çift fundus görünümü izlendi (Şekil-I).

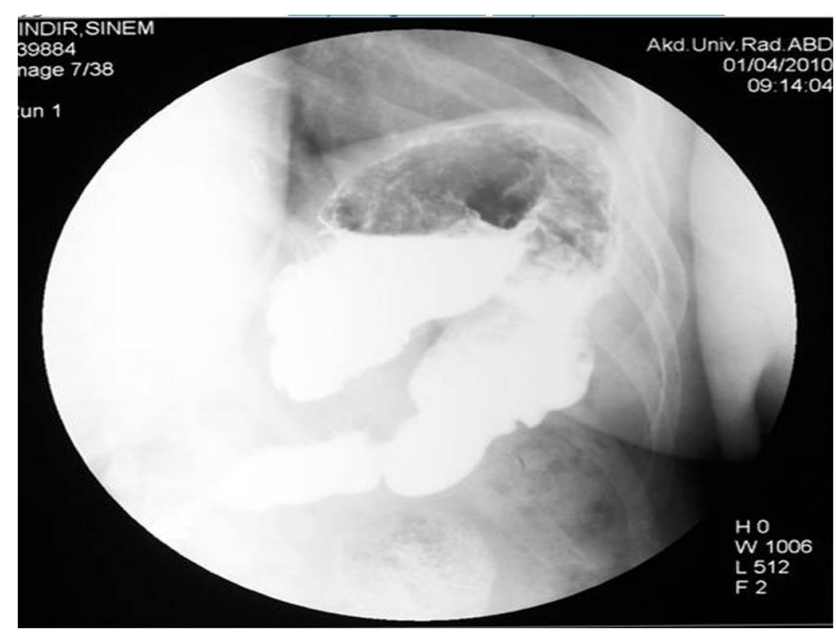

Şekil I: Baryumlu ösefagus mide görüntülemesinde mezoaksiyal tipte gastrikvolvulus (Olgu sunumu içinde 9. satırda)
Operasyona alınan olgunun yapılan laparoskopik görüntülemesinde mezoaksiyal tipteki gastrik volvulus dışında batın içi patolojik görüntü izlenmedi. Mide normal pozisyonuna getirilip büyük kurvatur anterior karın duvarına tespit edilerek laparoskopik anterior gastropeksi tamamlandı. Postoperatif 1. gün rejim-I ve takiben rejim-Il diyeti başlanan olgu 2. gün taburcu edildi. Postoperatif 10. günde çekilen baryumlu özofagus mide grafisinde normal özofagus, mide ve duodenum pasajı izlendi (Şekil-II)

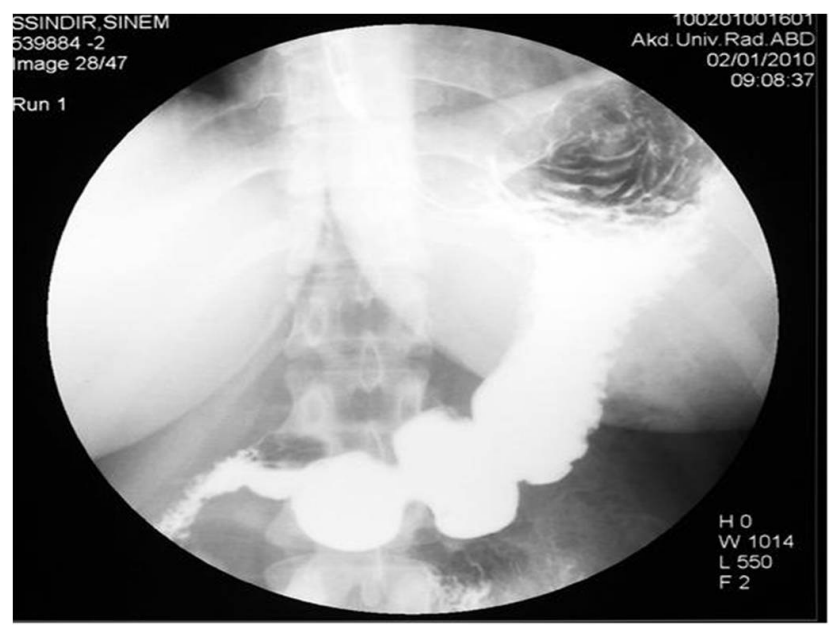

Şekil II: Postoperatif normal anatomik pozisyonunda mide (Olgu sunumu içinde son satırda)

\section{TARTIŞMA}

Gastrik volvulus nadir görülmekle birlikte tanısı için akılda bulundurulması gereken bir patolojidir. İnsidansı tam olarak bilinmemektedir (4). Midenin transvers veya longitudinal planda anormal rotasyonuna bağlı oluşmaktadır (5). Olguların \% 30'u mideyi sabitleyici ligamentlerin gevşek olması veya yokluğuna bağlı idiyopatik olabilirken \% 70'i paraözofageal herni, diafragma evantrasyonu, diafragma paralizisi, adezyon, neoplazm veya travmaya sekonder oluşabilir $(6,7)$. Akut, kronik ve kronik zeminde akut volvulus gelişmesi şeklinde ortaya çıkmakla beraber, kronik formu daha sık olarak görülmektedir. Gastrik volvulus organoaksiyal, mezenteroaksiyal ve kombine olmak üzere üç şekilde oluşabilir. Bunlardan organoaksiyal volvulus en sık görülen tip olup vakaların \% 59'unu oluşturmaktadır. Mezenteroaksiyal tip ise midenin transgastrik planda anormal rotasyonu sonucu gelişmekle birlikte vakaların \% 29'unu oluşturmaktadır $(2,6)$. 
Gastrik volvulus 1904'te Borchardt'ın tanımladığı triada göre epigastrik ağrı, öğürmeyle birlikte şiddetli kusma ve mideye nazogastrik tüpün yerleştirilememesi şeklinde kendini gösterebildiği gibi kronik volvuluslarda tekrarlayan ataklar şeklinde de ortaya çıkabilir (5).

Akut gastrik volvulusun tanısında gecikme sonucu iskemi, nekroz ve perforasyon gelişebilir (8). Bu olgular gastrointestinal kanama ve septik şok şeklinde de bulgu verebilir (5). Bu şekilde nekroz ve perforasyon gelişen gastrik volvuluslarda mortalite oranı \% 50'e ulaşabilmektedir (8). Kronik gastrik volvulus olgularıysa sıklıkla yemek yemeyle ilişkili distansiyon, epigastrik ağrı, kusma ve kilo kaybı şikayetleriyle başvurmaktadırlar (3).

Gastrik volvulusun tanısında altın standart görüntüleme baryumlu grafi olup oldukça duyarIı ve spesifiktir. Ayrıca endoskopi sırasında zor mide veya pilor entübasyonunda da gastrik volvulus düşünülmelidir $(9,10)$.

Gastrik volvulusun tedavisinde sıklıkla açık veya laparoskopik olarak yapılabilen anterior gastropeksi uygulanmaktadır. Bu yöntemde mide büyük kurvaturu, anterior abdominal duvara tespit edilmektedir $(9,10)$. Laparoskopik anterior gastropeksi, açık tekniğe göre hastanede kalış süresinin daha kısa olmasıyla birlikte daha güvenilir bir tekniktir (11). Midede nekroz gelişen akut gastrik volvulus vakalarında, subtotal veya total gastrektomi yapılmasını öneren yayınlar da bulunmaktadır $(9,10)$.

Gastrik volvulus oldukça nadir görülen bir durum olmakla birlikte genellikle tanı ve tedavisinde gecikme söz konusudur. Bunun sonucu olarak akut vakalar yüksek mortalite ile seyrederken, kronik vakalarda mortalite oranları düşük olup morbidite oranları yüksektir. Distansiyonla birlikte olan epigastriumda ağrı, öğürme, kusma ve kilo kaybı şikayetleriyle başvuran olgularda kronik gastrik volvulus düşünülmesi gereken bir tanıdır.

\section{KAYNAKLAR}

1- Gourgiotis S, Vougas V, Germanos S, Baratsis S. Acute gastric volvulus: diagnosis and management over 10 years. Digestive Surgery 2006;23(3):169-72.
2- Milne LW, Hunter JJ, Anshus JS, Rosen P. Gastric volvulus: two cases and a review of the literature. J Emerg Med 1994;12(3):299306.

3- Borchardt M. Zur pathologie und therapie des magen volvulus. Langenbecks Arch Klin Chir Ver Dtsch Z Chir 1904;74(1):243-60.

4- Machadoand NO, Rao BA. Gastric volvulus with identifiable cause in adults. Presentation and management. Saudi Medical Journal 2004;25(12):2032-4.

5- Carter R, Brewer LA, Hinshaw DB. Acute gastric volvulus: a study of 25 cases. American Journal of Surgery 1980;140(1):99106.

6- Wasselle JA, Norman J. Acute gastric volvulus: pathogenesis, diagnosis, and treatment. Am J Gastroenterol 1993;88(10):17804.

7- Godshall D, Mossallam U, Rosenbaum R. Gastric volvulus: case report and review of theliterature. J Emerg Med 1999;17(5):83740.

8- Farag S, Fiallo V, Nash S, Navab F. Gastric perforation in a case of gastric volvulus. American Journal of Gastroenterology 1996;91(9):1863-4.

9- Askew AR. Treatment of acute and chronic gastric volvulus. Annals of the Royal College of Surgeons of England 1978;60(4):326-8.

10- Palanivelu C, Rangarajan M, Shetty AR, Senthilkumar R. Laparoscopic suture gastropexy for gastric volvulus: a report of 14 cases. Surgical Endoscopy and Other Interventional Techniques 2007;21(6):863-6.

11- Januschowski R. Endoscopic repositioning of the up side down stomach and its fixation by percutaneous endoscopic gastrostomy. Dtsch Med Wochenschr 1996;121(41):1261-4. 